\title{
A Utilização da Entrevista da Narrativa do Adoecimento Mcgill-Mini na Abordagem de Pacientes Poliqueixosos por Alunos do Internato Rotatório de Medicina de Família e Comunidade (Mfc)
}

\author{
Rocha, Hélio Antonio; Souza, Alicia Navarro Dias de \\ Universidade Federal do Rio de Janeiro — hearoch@gmail.com
}

Introdução: Pacientes que apresentam sintomas somáticos que não podem ser bem explicados pelos diagnósticos médicos constituem de um quarto a metade da demanda de atendimento por serviços de saúde no cenário da atenção primária e secundária. São necessários recursos a fim de qualificar a escuta e o acolhimento a estes pacientes, a fim de melhorar a abordagem a esta clientela. Objetivos: Avaliar que contribuições a utilização de uma entrevista que busca colher a narrativa de adoecimento do paciente pode trazer à formação do aluno que passa pelo internato de MFC. Avaliar se os internos conseguem dar ao paciente o lugar de expert da sua narrativa de adoecimento. Métodos: no período de um ano, trezes alunos do internato rotatório em MFC foram capacitados a aplicar a Entrevista McGill-MINI. Cada um participou da entrevista de dois a três pacientes poliqueixosos. Foram registradas dezessete entrevistas. Todas elas foram gravadas em áudio e transcritas. o material foi submetido à análise de conteúdo. Resultados: a utilização da Entrevista McGill-MINI contribuiu para uma experiência de inclusão da perspectiva do paciente no atendimento realizado pelo aluno do internato. Dar ao paciente o lugar de expert no relato de sua experiência sobre seu problema de saúde foi um desafio. Houve uma tendência dos internos tentarem introduzir nas entrevistas, questões da anamnese convencional a fim de esclarecer os sintomas descritos pelos pacientes. Os dados sugerem que a Entrevista McGill-MINI pode contribuir a compreensão dos determinantes psicossociais da doença, assim como para uma relação médicopaciente mais dialógica, onde haja um compartilhamento de saberes que tenha implicação na construção de um plano terapêutico conjunto. a compreensão da experiência de adoecimento, permitida pela realização da entrevista, trouxe informações adicionais à anamnese tradicional com implicações na construção do raciocínio clínico e na elaboração de um plano terapêutico para além da prescrição de medicamentos. com as informações colhidas, os alunos puderam indicar a participação em atividades grupais realizadas na ESF e na comunidade, assim como psicoterapia e articulação entre ESF e a rede de saúde mental. Esse tipo de proposta envolve a incorporação da integralidade e da intersetorialidade no raciocínio clínico. Mesmo quando os internos não conseguiram elaborar um plano terapêutico específico para o caso, eles puderam abordar, conversar melhor com os pacientes. Esta experiência possibilitou que os alunos expusessem críticas ao ensino médico centrado na doença e no estudo das especialidades. Conclusão: a incorporação desta entrevista no atendimento aos pacientes poliqueixosos pôde proporcionar um atendimento mais humanizado, centrado na pessoa, fortalecendo a construção do vínculo terapêutico entre estudante e paciente.

Rocha, Hélio Antonio; Souza, Alicia Navarro Dias de. A Utilização da Entrevista da Narrativa do Adoecimento Mcgill-Mini na Abordagem de Pacientes Poliqueixosos por Alunos do Internato Rotatório de Medicina de Família e Comunidade (Mfc). In: Anais do Congresso Internacional de Humanidades \& Humanização em Saúde [= Blucher Medical Proceedings, num.2, vol.1]. São Paulo: Editora Blucher, 2014. ISSN 2357-7282

DOI 10.5151/medpro-cihhs-10671 